\title{
Survival of isolated skin explants in remote interaction with stratiform periodic structures
}

\author{
I.E. Nikityuk ${ }^{1}$, K.A. Afonichev ${ }^{1}$, M.S. Nikitin ${ }^{1}$, V.V. Petrash ${ }^{2}$, V.A. Kubasov ${ }^{3}$ \\ ${ }^{1}$ H. Turner National Medical Research Center for Children's Orthopedics and Trauma Surgery, Saint Petersburg, Russian Federation \\ ${ }^{2}$ Private Institution Educational Organization of Higher Education REAVIZ University, Saint Petersburg, Russia \\ ${ }^{3}$ D.V. Efremov Scientific Research Institute of Electrophysical Apparatus (NIIEFA), Saint Petersburg, Russia
}

\begin{abstract}
Full-thickness skin grafts are used in reconstructive surgeries. Objectives Experimental study of the possibility of long-term preservation of viable skin grafts in severely impaired trophics at remote interaction with entities having stratiform periodic structure. Material and methods Full-thickness skin was excised from the rabbits' backside and dissected into explants sized $1.0 \times 1.0 \mathrm{~cm}$. The samples $(\mathrm{n}=81)$ were divided into three groups and thermostated for 2 days at $37^{\circ} \mathrm{C}$ at a various distance from the metal (aluminum) presented as a 20-layer package of smooth foil forming a stratiform periodic structure (SPS) (series I), chaotic layers of squeezed foil (series II) and a single-piece sheet (series III). Histological analysis was performed for the three series to evaluate the explants' viability after the thermostating. Results The highest survival estimates were seen in experimental explants of series I that interacted with the SPS of stratified foil layers. The wave nature of such remote interaction was suggested with delayed dystrophic and necrotic processes developing in the skin samples. Experimental samples of series III appeared to be less viable. The explant vitality in series II was sharply reduced due to rapidly spreading necrosis. Conclusion Skin explants were shown to retain viability for a longer time when interacting remotely with stratiform periodic structures in the absent trophics. These promising results can be practical for the development of wound dressings to improve survival of full-thickness skin transplantation in reconstruction of deep skin defects.
\end{abstract}

Keywords: deep burns, full-thickness skin explants, epidermis, stratiform periodic structure, photonic crystal

\section{INTRODUCTION}

Full-thickness skin grafts are used in reconstructive surgery to cover extensive skin lesions caused by deep burns. Strategies to promote skin regeneration with wound covering materials have been always the focus of investigations to ensure complete restoration of the integrity of the skin. There have been attempts made to use thin sheets of metal made of silver [1], aluminium, lead, and gold [2] for medical applications to superficial burn wounds. However, different approaches were needed for deep skin wounds, and multilayer thin-film wound coatings (multilayer films) consisting of many alternating thinnest layers of metal and dielectric were offered [3]. Such stratiform periodic structures (SPS) are of great scientific interest due to the high potential use in biomedicine [4] and tissue engineering, in particular, to improve regeneration of biological tissues $[5,6]$.
The biological properties of SPS are being actively studied. Experiments have shown that SPS promotes the differentiation of progenitor cells into mature cells of the nervous [7] and bone [8] tissues. With respect to skin regeneration, however, there is a limited number of papers to support the stimulating effect of SPS on cellular activity despite the use of composite scaffold matrices in the clinic [9], and more studies are needed to explore this topic. This necessitates the search for optimal wound coverings with the current medical needs for a high-quality wound treatment system to serve the basis for the development of new technologies for regenerative surgery.

Objectives To experimentally explore the possibility of long-term preservation of viable skin grafts in severely impaired trophics at remote interaction with metal material molds (MMM) having SPS.

\section{MATERIAL AND METHODS}

The study was conducted in the experimental laboratory of the H. Turner National Medical Research Center for Children's Orthopedics and Trauma Surgery, Ministry of Health of the Russian Federation, using Chinchilla rabbits of both sexes aged 5-6 months with a body weight of $2.2-2.5 \mathrm{~kg}$. The study received a favourable opinion from the relevant research ethics committee of the Center and met international and national regulations for the treatment of laboratory animals. The manipulations with animals were performed under general anesthesia with the use of a mixture of tiletamine hydrochloride and zolazepam hydrochloride (Zoletlil 100, Vibrac, France). The dosage for each animal was selected individually at $15 \mathrm{mg} / \mathrm{kg}$ of animal weight. Anesthesia was performed with intramuscular injection. 
Each rabbit had the hair cut off at the backside. Full-thickness skin measuring $3.0 \times 3.0 \mathrm{~cm}$ was excised from the rabbits' backside in sterile conditions and dissected into 9 explants sized $1.0 \times 1.0 \mathrm{~cm}$. Each explant was wrapped in a thin food-grade plastic film and placed on textolite substrates of plastic containers with the outer surface facing up to prevent drying. A thin layer of distilled water was poured into the bottom of the containers to ensure higher humidity of the air environment. Metal samples of the shape tested were placed on textolite substrates next to the explants at a distance of $1 \mathrm{~cm}$ in increments starting from $0 \mathrm{~cm}$ in series of experiments. The maximum distance was adjusted to $8 \mathrm{~cm}$. The containers were sealed with lids and placed for two days in a thermostat with temperature of $37^{\circ} \mathrm{C}$ being comparable to the body temperature of warm-blooded animals. Experiments with explants of the experimental group were conducted in 3 series. Samples of MMM were manufactured for each series.

MMM samples were made from long continuous strips of aluminum foil 20 microns thick and bent into 20 layers with a rectangular "accordion" sized $6.0 \times 10.0 \mathrm{~cm}$ and $0.4 \mathrm{~mm}$ thick in series I of the experiment (Fig. 1a). The foil layers were pressed tightly together. With each layer of aluminum being covered with a natural thin $\mathrm{A} 12 \mathrm{O} 3$ oxide film $100 \mathrm{~nm}$ thick, the samples had alternating layers of metal and dielectric forming SPS. The foil tape sized similar to that in series I was squeezed into a ball and then pressed into a rectangular plate with an average size of $6.0 \times 10.0 \mathrm{~cm}$ in series II (Fig. 1b). The metal sample was represented by a single-piece sheet made of A5(1050)AD1 aluminium sized $6.0 \times 10.0 \mathrm{~cm}$ $0.5 \mathrm{~mm}$ thick in series III.

The MMM samples were co-aligned with the explants and faced them with a smaller side in all experiments. The experiments were repeated 3 times for each distance in each series with 81 skin explants

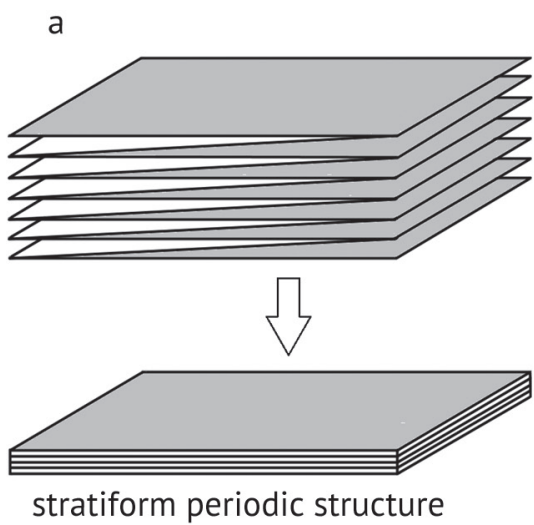

used in the experimental group. MMM samples were boiled for 5 minutes in distilled water and dried to be re-used. Three control explants were placed in similar plastic containers with identical condition with no interaction with the MMM and were thermostated for 2 days. After thermostating, the skin explants were fixed in a $10 \%$ Kaiserling solution, passed through a series of progressively increasing concentration of alcohol in the STP 120 spin tissue processor with carousel system (Thermo Fisher Scientific, Finland) and embedded in paraffin in the EC 350 Tissue Embedding Center (Thermo Fisher Scientific, Finland). The resulting paraffin blocks were sectioned with the sliding microtome HM 430 (Thermo Fisher Scientific, Finland). The sections were stained with Mayer's aqueous-alcoholic eosin and hematoxylin. Preparations were morphologically examined and digital images obtained with a light laboratory microscope Axio Lab.A1(Carl Zeiss, Germany). Histological examination of skin explants allowed estimation of the survival rate after thermostating. Four structures of the animal's skin evaluated included the epidermis, hair follicles, the dermis and the muscle. The intact structure scored 1, partial cell necrosis reduced the score to 0.5 , and complete cell necrosis scored ' 0 '. The maximally preserved viability of the skin explant scored 4, and totally necrotic explant scored ' 0 '.

Statistical data analysis was performed with the nonparametric Kruskal-Wallis test with the level of statistical significance set at $p<0.05$. At the next stage, a pairwise comparison of the samples was performed using the nonparametric Mann-Whitney test with the Bonferoni correction when estimating the $p$ value. The critical level of significance was calculated using the formula $p=0.05 /$ number of comparisons $=0.05 / 3=0.018$. The data were presented as a median $(\mathrm{Me})$ with an interquartile interval of $25 \%-75 \%\left[\mathrm{Q}_{1}-\mathrm{Q}_{2}\right]$.

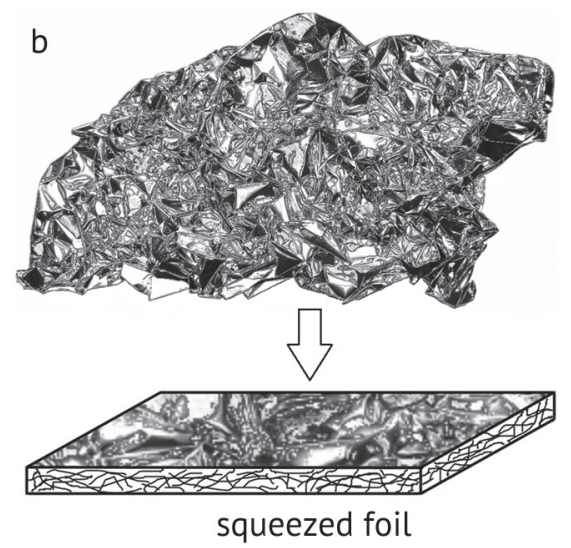

Fig. 1 Diagram showing MMM manufactured of aluminium foil as (a) stratiform periodic structure; (b) squeezed foil 


\section{RESULTS}

Histological examination of sections of intact rabbit skin in the epithelial layer revealed large cells with distinct nuclei. Hair follicles were represented by large clusters of round and oval cells. There were a large number of connective tissue cells and collagen fibers in the dermis. The muscle layer of rabbits located between the dermis and subcutaneous tissue was represented by striated tissue, muscle fibers with many elongated nuclei and connective tissue layers with nuclei well stained and easily identified (Fig. 2).

The histological picture of the control explants after two days of thermostating was characterized by signs of pronounced degeneration in all layers. The sections showed total necrosis of the epithelium and the dermis with only the contours remained from the hair follicles. The muscle layer appeared as a shapeless, almost homogeneous mass that was not properly stained. Neither cell nuclei nor their components could be found in the structures (Fig. 3).

The maximum survival rate of explants was identified at the direct contact with MMM samples in all series of the experimental group. The highest viability score was seen in skin samples of series I with the structures well maintained in the layers with properly stained and identified cell nuclei. The explants of series III showed a lower vitality score. The lowest survival rate was found in explants in series II despite their direct contact with squeezed aluminium foil with resultant total necrosis of the muscle layer, absent muscle fibers appeared as homogeneous masses without nuclei. Single nuclei were seen in the intermuscular connective tissue. Necrosis was detected in the dermis and was severe enough in some skin samples. Cells with stained nuclei were seen only in the epidermis and hair follicles. However, the number of nuclei components was reduced with the less intense staining. The skin explants removed from MMM samples demonstrated the decreased survival rate of different extent in all series (Fig. 4).
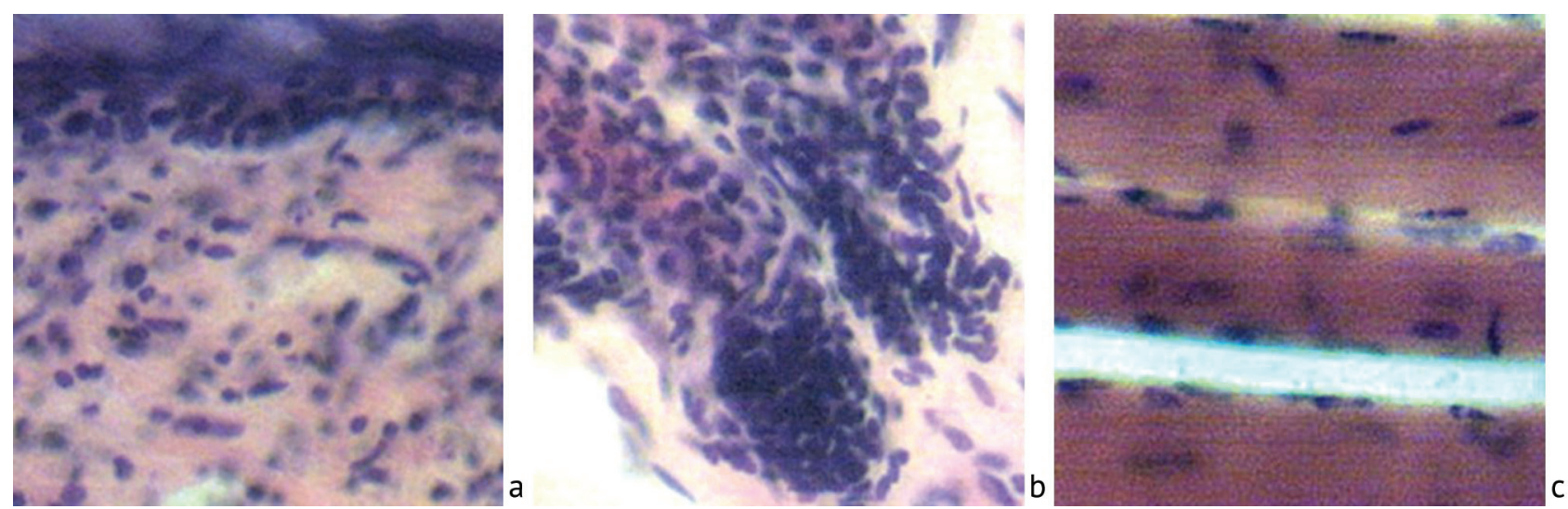

Fig. 2 Section of the normal rabbit skin showing $(\boldsymbol{a})$ the corneal and epithelial layers of the epidermis with the adjacent dermis; (b) the hair follicle; (c) the muscle layer. The nuclei of the cells of the epidermis, dermis, hair follicles and muscles are well stained. Stained with hematoxylin and eosin, magnification 400
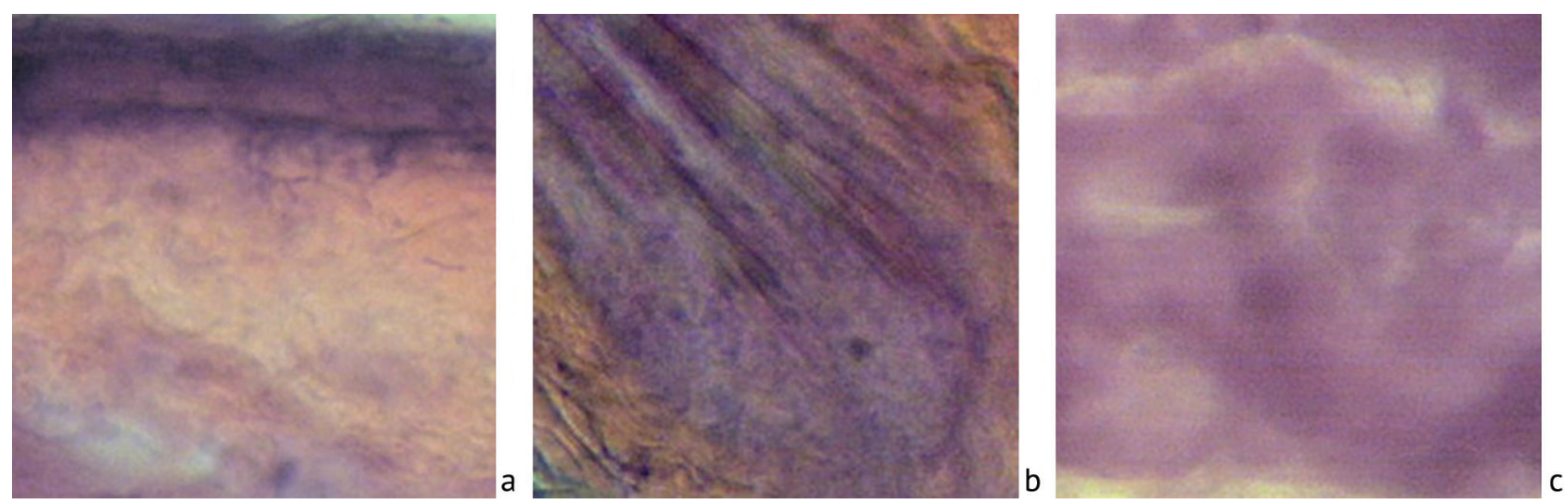

Fig. 3 A section of the skin explant of a control rabbit at 2 days of thermostating showing $(\boldsymbol{a})$ the corneous and epithelial layers of the epidermis with the adjacent dermis; $(\boldsymbol{b})$ the hair follicle; $(\boldsymbol{c})$ the muscle layer. Lesion of cell nuclei, necrosis and destruction of tissues seen in all layers. Stained with hematoxylin and eosin, magnification 400 


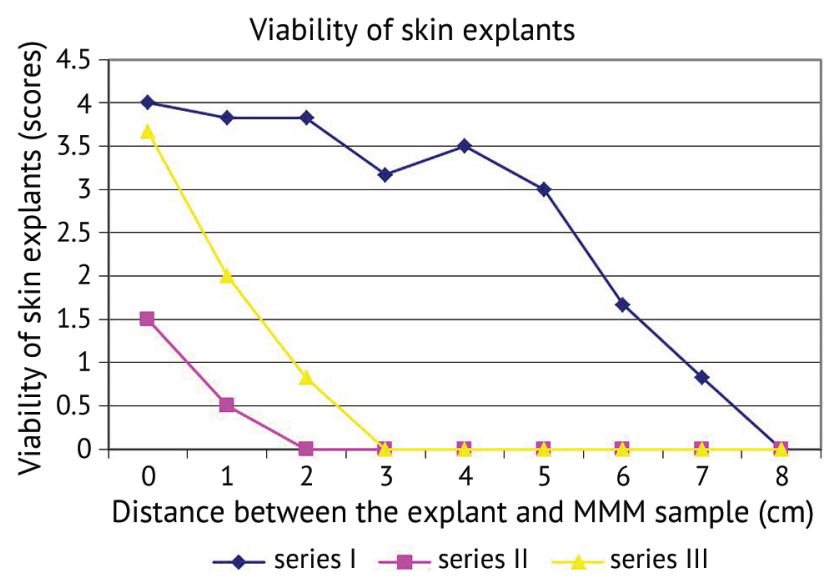

Fig. 4 Viability of skin explants measured depending on the distance from the MMM sample at thermostating in experiments of series I, II and III

With an increased distance between the MMM samples and the explants, the greater vitality was revealed in series I as compared to that in series II and III. Histologically, it appeared as less pronounced signs indicating dystrophy and necrois in the tissues of the skin samples of series I. Increased distance primarily led to the death of the muscle layer that appeared as clusters of shapeless, poorly stained masses with no cell nuclei. With a further increase in the distance between the MMM and explants, the dermis appeared dystrophic with a decreased number of nuclear components and impaired fibrous structure. The cells of the epidermis and hair follicles showed the greatest viability with decreased nuclei that retained sensitivity to stain, although to a lesser extent compared to the norm (Fig. 5). When the distance between the MMM and explants was critical, the samples appeared necrotic and destructured with no stained nuclear components in all layers of the skin, and the vitality of the skin samples scored ' 0 '.

Table 1 shows the Kruskal-Wallis calculations to test the null hypothesis of the median of explant survival rates being identical within each of the three numerical series. The p-value was found to be less than 0.05 with a statistically significant difference between the medians of explant survival rates when interacting with different metal samples. A paired comparison of the samples was additionally performed to determine the medians of which series differed significantly from the others (Table 2).
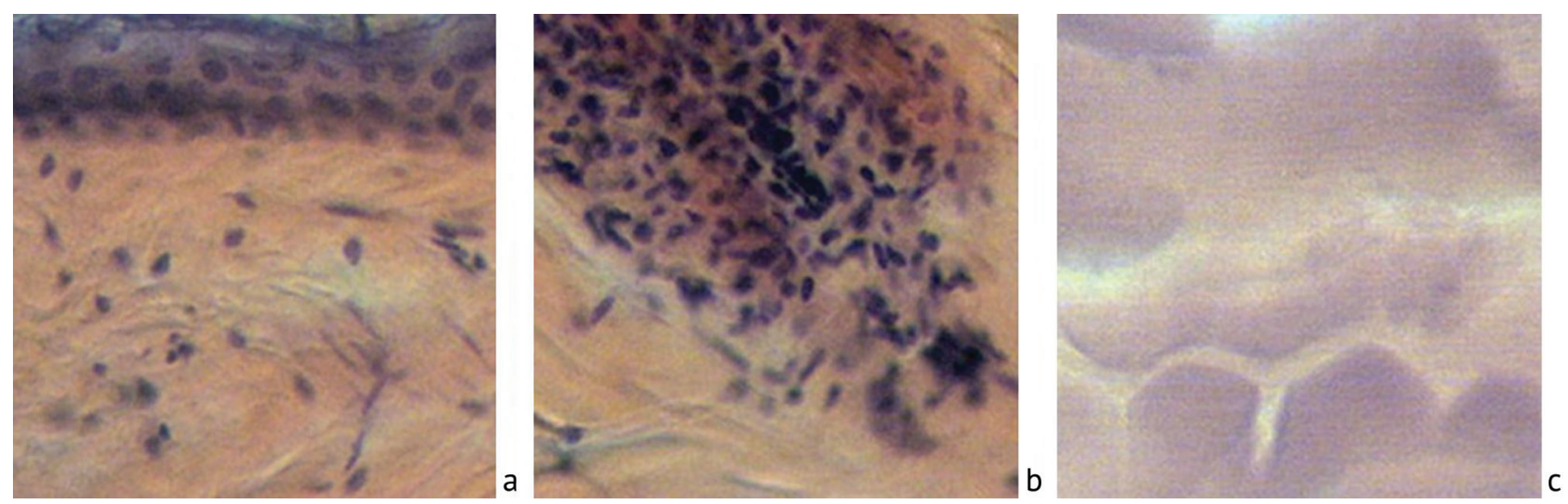

Fig. 5 A section of the skin explant of series I at 2 days of thermostating at a distance of $6.0 \mathrm{~cm}$ from the foil SPS showing (a) the corneous and epithelial layers of the epidermis with the adjacent dermis; $(\boldsymbol{b})$ the hair follicle; $(\boldsymbol{c})$ the muscle layer. Reduced number and intensity of stain of cell nuclei in the dermis and hair follicles. Necrosis and destruction of muscle layer with lesion of cell nuclei. Stained with hematoxylin and eosin, magnification 400

Table 1

Comparative evaluation of explant survival rates when interacting with different MMM samples (Kruskal-Wallis test)

\begin{tabular}{|l|c|c|c|c|}
\hline \multicolumn{1}{|c|}{ Series } & Number of explants & Mean rank & Medial & p-value \\
\hline Series I - SPS foil & 27 & 61.0 & 3.0 & \multirow{2}{*}{0.000} \\
\hline Series II - squeezed foil & 27 & 27.6 & 0 & 0 \\
\hline Series III - single-piece sheet & 27 & 34.4 & 0 & \\
\hline
\end{tabular}

Table 2

Comparative evaluation of graft survival rates when interacting with different FMM samples (Mann-Whitney test)

\begin{tabular}{|c|c|c|c|c|}
\hline Series & Number of explants & Explant survival (scores) $\mathrm{Me}\left[\mathrm{Q}_{1}-\mathrm{Q}_{2}\right]$ & $\mathrm{p}$ & p-critical \\
\hline Series I - SPS foil & 27 & $3.0[0-4.0]$ & \multirow{3}{*}{$\begin{array}{l}\mathrm{P}^{1-2}=0.000 \\
\mathrm{p}^{1-3}=0.000 \\
\mathrm{p}^{2-3}=0.160\end{array}$} & \multirow{3}{*}{0.018} \\
\hline Series II - squeezed foil & 27 & $0[0-0]$ & & \\
\hline Series III - single-piece sheet & 27 & $0[0-1.0]$ & & \\
\hline
\end{tabular}

Note: $\mathrm{p}^{1-2 ; 1-3 ; 2-3}$ - significant differences between the groups 
The median survival rate of explants in series I was shown to be significantly superior to that in series II and III of experiments (Table 2). There were no significant differences in the median survival rate of explants in series II and III. This could mean that MMM samples manufactured as SPS foil could primarily contribute to maintained viability of skin explants after the thermostating with completely impaired trophics.

\section{DISCUSSION}

Ultra-weak photon emission (UPE) is reported to be generated from the human epidermis and the dermis in the spectrum of 300-800 $\mathrm{nm}[10,11]$ and also from the skin explants [12]. It is assumed that the intrinsic electromagnetic radiation emitted by biological tissues contains information about the functional state of the cells [13]. Reasonably good evidence exists on the bioregulatory role of endogenous physical fields produced by living cells [14] that can lead to a targetspecific change in the properties and vital activity of other cells [15]. There is also the possibility of using the intrinsic transformed physical fields of skin explants to improve the survival in impaired trophics [16].

The present study suggested that thermostated skin samples could maintain the vitality of different extent in the proximity of a MMM entity depending on the structure. It would be logical to assume, therefore, that cellular and humoral factors could change the biological activity of skin explants during the noncontact interaction with MMM as a result of an external physical effect, presumably of a wave nature. This could result in suppression of dystrophy and necrosis in the skin samples. The highest survival rate was found in explants of series I after the thermostating close to MMM represented as SPS. The resulting effect can be explained by the following assumptions. In series I, the skin explant interacted with an MMM that included alternating layers of aluminum foil that also incorporated a thin film of aluminum oxide (corundum) with dielectric and semiconductor properties. This type of SPS can generate nonlinear optical effects and the transformation of electromagnetic radiation changing its spectral characteristics [17]. The skin of mammals includes the epidermis, which is also an SPS represented by a set of alternating layers with different capabilities to transform electromagnetic waves [18]. This property of the epidermis is characteristic of photonic crystals that can also transform physical radiation in a wide range of the spectrum [19]. Such SPSs have electrical conductivity [20], the ability to store electrical energy [21], biocompatibility [22], and the ability to impact the cellular activity, which is manifested by improved regeneration of biological tissues [23].

In series I of the study, the SPS made of foil was likely to play the role of a matrix structurizer that could elicit electrostatic resonance phenomena at the remote interaction with the SPS of the skin explant with characteristic effect on cell activity [24]. In the present study, the biological effect of this interaction was provided by the long-term preservation of the viability of the skin explants in the environment of impaired trophics. The MMM samples of series II and III were not manufactured with strictly arranged layers and were represented either by a randomly structured and squeezed foil or by a single-piece aluminium sheet with disordered metal microcrystals. The factor could cause a significant decrease in the viability of skin explants after they were thermostated in the proximity of such MMMs. Further study of the biological activity of materials that have a strictly arranged structure can be practical for skin regeneration and the development of new wound dressings.

\section{CONCLUSION}

The findings of the series suggested a remote interaction between skin explants and stratiform periodic structures, presumably of a wave nature. Skin explants were shown to retain viability for a longer time when interacting remotely with stratiform periodic structures in the absent trophics. These promising results can be practical for the use of chemically and biologically inert SPS in reconstructive surgery as wound dressings to improve survival of full-thickness skin transplantation in reconstruction of deep skin defects.

Funding The authors received no financial support for the research and/or authorship of this article.

Declaration of Conflicting Interests The authors declared no potential conflicts of interest with respect to the authorship and/or publication of this article.

Compliance with ethical standards and laws The manipulations were produced in accordance with the Guidelines for the maintenance of laboratory animals in vivariums of research institutes and educational institutions" RD-APK 3.10.07.02-09 and The European Convention for the protection of vertebrate animals used for experimental and other scientific purposes and Directive 2010/63/EU of the European Parliament and of the Council of 22 September 2010 on the protection of animals used for scientific purposes. The study received a favourable opinion from the relevant research ethics committee of the. Turner National Medical Research Center for Children's Orthopedics and Trauma Surgery, Ministry of Health of the Russian Federation. 


\section{REFERENCES}

1. Hein W. Der heutige Stand der örtlichen Verbrennungsbehandlung [The current state of local burn treatment]. Der Chirurg, 1957, vol. 28, no. 3, pp. 127-135. (in German)

2. Arev T.Ia. Termicheskie porazheniia [Thermal lesions]. L., Meditsina, 1966, 704 p. (in Russian)

3. Nikitiuk I.E., Kubasov V.A., Petrash V.V., Afonichev K.A. Eksperimentalnoe primenenie ranevykh pokrytii so svoistvami fotonnykh kristallov dlia vosstanovleniia glubokikh defektov kozhnykh pokrovov [Experimental application of wound coatings with the properties of photonic crystals for the restoration of deep defects of skin integuments]. Ortopediia, Travmatologiia i Vosstanovitelnaia Khirurgiia Detskogo Vozrasta, 2016, vol. 4, no. 3, pp. 63-70. (in Russian)

4. Richardson J.J., Björnmalm M., Caruso F. Multilayer assembly. Technology-driven layer-by-layer assembly of nanofilms. Science, 2015, vol. 348, no. 6233, pp. aaa2491. DOI: $10.1126 /$ science.aaa2491

5. Shukla A., Almeida B. Advances in cellular and tissue engineering using layer-by-layer assembly. Wiley Interdiscip. Rev. Nanomed. Nanobiotechnol., 2014, vol. 6, no. 5, pp. 411-421. DOI: 10.1002/wnan.1269

6. Gentile P., Carmagnola I., Nardo T., Chiono V. Layer-by-layer assembly for biomedical applications in the last decade. Nanotechnology, 2015, vol. 26 , no. 42, pp. 422001. DOI: 10.1088/0957-4484/26/42/422001

7. Jan E., Kotov N.A. Successful differentiation of mouse neural stem cells on layer-by-layer assembled single-walled carbon nanotube composite. Nano Lett., 2007, vol. 7, no. 5, pp. 1123-1128. DOI: 10.1021/n10620132

8. Zhang J., Fu Y., Mo A. Multilayered titanium carbide MXene film for guided bone regeneration. Int. J. Nanomedicine, 2019, vol. 14, pp. 1009110103. DOI: 10.2147/IJN.S227830

9. Chaudhari A.A., Vig K., Baganizi D.R., Sahu R., Dixit S., Dennis V., Singh S.R., Pillai S.R. Future prospects for scaffolding methods and biomaterials in skin tissue engineering: A review. Int. J. Mol. Sci., 2016, vol. 17, no. 12, pp. 1974. DOI: 10.3390/ijms17121974

10. Tsuchida K., Iwasa T., Kobayashi M. Imaging of ultra-weak photon emission for evaluating the oxidative stress of human skin. J. Photochem. Photobiol. B, 2019, vol. 198, pp. 111562. DOI: 10.1016/j.jphotbiool.2019.111562

11. Calcerrada M., Garcia-Ruiz C. Human ultra-weak photon emission: key analytical aspects, results and future trends - a review. Crit. Rev. Anal. Chem., 2019, vol. 49, no. 4, pp. 368-381. DOI: 10.1080/10408347.2018.1534199

12. Ou-Yang H. The application of ultra-weak photon emission in dermatology. J. Photochem. Photobiol. B, 2014, vol. 139, pp. 63-70. DOI: 10.1016/j. jphotobiol.2013.10.003

13. Laager F. Light based cellular interactions: hypotheses and perspectives. Front. Phys., 2015, vol. 3, article 55. DOI: 10.3389/fphy.2015.00055

14. Dlask M., Kukal J., Poplová M., Sovka P., Cifra M. Short-time fractal analysis of biological autoluminescence. PLoS One, 2019, vol. 14, no. 7, pp. e0214427. DOI: 10.1371/journal.pone.0214427

15. Levin M., Martyniuk C.J. The bioelectric code: An ancient computational medium for dynamic control of growth and form. Biosystems, 2018, vol. 164, pp. 76-93. DOI: 10.1016/j.biosystems.2017.08.009

16. Petrash V.V., Nikitiuk I.E. Ispolzovanie effektov fotonno-volnovykh vzaimodeistvii biosistem s veshchestvom v prodlenii zhiznesposobnosti izolirovannykh kozhnykh loskutov [Using the effects of photon-wave interactions of biosystems with substance in prolonging the viability of isolated skin flaps]. Vestnik Sankt-Peterburgskoi Gos. Med. Akad. im. I.I. Mechnikova, 2007, vol. 8, no. 1, pp. 118-121. (in Russian)

17. Aktsipetrov O.A., Dolgova T.V., Fedyanin A.A., Murzina T.V., Inoue M., Nishimura K., Uchida H. Magnetization-induced second- and third harmonic generation in magnetophotonic crystals. J. Optical Soc. Am., 2005, vol. 22, no. 1, pp. 176-186. DOI: 10.1364/JOSAB.22.000176

18. Ilinskii A.V., Silva-Andrade F., Shadrin E.B., Samoilov V.O., Orbeli A.L. Biologicheskie struktury kak fotonnye obekty [Biological structures as photon objects]. Biofizika, 2006, vol. 51, no. 4, pp. 743-748. (in Russian)

19. Kubasov V.A., Nikitiuk I.E., Petrash V.V., Voroshilov (Shtrupp) B.M. Epidermis - sloisto-periodicheskaia biostruktura so svoistvami fotonnykh kristallov [Epidermis is a layered periodic biostructure with the properties of photonic crystals]. M., Editus, 2019, 236 p. (in Russian) DOI: 10.18720/ SPBPU/2/z19-2

20. Ling Z., Ren C.E., Zhao M.Q., Yang J., Giammarco J.M., Qiu J., Barsoum M.W., Gogotsi Y. Flexible and conductive MXene films and nanocomposites with high capacitance. Proc. Natl. Acad. Sci. USA, 2014, vol. 111, no. 47, pp. 16676-16681. DOI: 10.1073/pnas.1414215111

21. Anasori B., Lukatskaya M., Gogotsi Y. 2D metal carbides and nitrides (MXenes) for energy storage. Nat. Rev. Mater., 2017 , vol. 2, pp. 16098. DOI: $10.1038 /$ natrevmats.2016.98

22. Ghidiu M., Lukatskaya M.R., Zhao M.Q., Gogotsi Y., Barsoum M.W. Conductive two-dimensional titanium carbide 'clay' with high volumetric capacitance. Nature, 2014, vol. 516, no. 7529, pp. 78-81. DOI: 10.1038/ nature 13970

23. Zhang S., Xing M., Li B. Biomimetic layer-by-layer self-assembly of nanofilms, nanocoatings, and 3D scaffolds for tissue engineering. Int. J. Mol. Sci., 2018, vol. 19, no. 6, pp. 1641. DOI: 10.3390/ijms19061641

24. Nikitiuk I.E., Petrash V.V., Kubasov V.A., Zakharova N.G., Ilina L.V. Matrichnyi gistogenez biologicheskikh tkanei pri ikh regeneratsii na implantatakh so sloistoi periodicheskoi strukturoi [Matrix histogenesis of biological tissues during their regeneration on implants with layered periodic structure]. Fundamentalnye Issledovaniia, 2012, no. 7-2, pp. 372-376. (in Russian)

Received: 28.10 .2020

\section{Information about the authors:}

1. Igor E. Nikityuk, M.D., Ph.D.,

H. Turner National Medical Research Center for Children's Orthopedics and Trauma Surgery, Saint Petersburg, Russian Federation, ORCID: https://orcid.org/0000-0001-5546-2729,

Email: femtotech@mail.ru

2. Konstantin A. Afonichev, M.D., Ph.D.,

H. Turner National Medical Research Center for Children's Orthopedics and Trauma Surgery, Saint Petersburg, Russian Federation, ORCID: https://orcid.org/0000-0002-6460-2567,

Email: afonichev@list.ru

3. Maxim S. Nikitin, M.D.,

H. Turner National Medical Research Center for Children's Orthopedics and Trauma Surgery, Saint Petersburg, Russian Federation, ORCID: https://orcid.org/0000-0001-8987-3489,

Email: doknikitin@yandex.ru

4. Vladimir V. Petrash, Ph.D. of Biological Sciences, Professor,

REAVIZ University, Saint Petersburg, Russian Federation,

ORCID: https://orcid.org/0000-0003-4209-3762,

Email: vlapetrash@yandex.ru

5. Vitaly A. Kubasov, Ph.D. of Physico-mathematical Sciences,

Scientific and Technical Center «Synthesis», D.V. Efremov Scientific Research Institute of Electrophysical Apparatus (NIIEFA), Saint Petersburg, Russian Federation,

ORCID: https://orcid.org/0000-0001-8531-4655,

Email: kubasov@sintez.niiefa.spb.su 